\title{
Research on the Status and Problems of Fresh E-commerce Development
}

\author{
Qiuyue Wang \\ Institute of Management Engineering, Zhengzhou University, Zhengzhou, China \\ zzuwangqiuyue@163.com
}

Keywords: Fresh e-commerce, Development problems, Targeted suggestions.

\begin{abstract}
Fresh e-commerce is known as "the last blue ocean" in the field of e-commerce. In 2017, the transaction scale of fresh e-commerce market exceeded 100 billion yuan in China, and it has a trillion market in the future. Although fresh e-commerce has a good development prospect, most fresh e-commerce companies are still in a loss. Is there any problem with fresh e-commerce? Based on the this problem, this paper studies the current status of fresh e-commerce and summarizes the following developments problems: (1)high cost of cold chain logistics. (2)the coverage of cold chain logistics is unbalanced. (3)Fresh products quality and industry standards are not uniform. (4) High loss rate during transportation of fresh produce. And then this paper presents targeted suggestions.
\end{abstract}

\section{Introduction}

With the rapid development of the Internet and the indepth implementation of agricultural supply-side structural reform, fresh agricultural products have gradually broken through the traditional retail methods and embarked on the journey of fresh e-commerce. It is no doubt that the combination of e-commerce and fresh products is opening up a new world for the sales of fresh products. According to the data released by the Penguin Intelligence, the total transaction volume of fresh e-commerce market was 141.8 billion yuan in China in 2017.

Although the total transaction volume of fresh e-commerce market has exceeded 100 billion yuan in China, the supply of fresh products can not meet the growing needs of people. Fresh e-commerce is known as the "last blue ocean" in the field of e-commerce, and it has a trillion yuan market. It shows that the fresh e-commerce market has a good prospect for development. However, in 2016, $88 \%$ of more than 4,000 fresh e-commerce companies were in a state of loss in China, and some comapnies even closed down. It has brought a bit of bleakness to the fresh e-commerce industry.

\section{Development status of fresh e-commerce}

As the first fresh e-commerce website in China, the establishment of yiguo.com marked that China's fresh e-commerce has officially entered the initial stage of development. At present, there are four modes that occupy the main position of the fresh e-commerce marke, as shown in Table 1. 
Table 1 Four models of fresh e-commerce and their representative enterprises.

\begin{tabular}{cc}
\hline The development model of fresh e-commerce & The representative enterprises \\
\hline Platform-type fresh e-commerce & Alibaba, Jingdong \\
Vertical-type fresh e-commerce & sfbest.com, benlai.com \\
O2O-type fresh e-commerce & Yonghui Superstores \\
New retail-type fresh e-commerce & freshhema.com \\
\hline
\end{tabular}

\subsection{Platform-type fresh e-commerce}

Platform-type fresh e-commerce is a platform that integrates buyers, sellers and third-party logistics of fresh products, including the entire transaction process, its cold chain logistics often provided by a third party (Zhiyong Qin, Jinzhan Feng, 2017). Its main advantage is that fresh products sellers can achieve rapid sales growth by relying on the huge customer flow of the platform. However, it also has limitations, such as complex circulation link makes high loss rate of fresh products and merchants need to pay fees for entering platform (Linhui Dai, Yuhao Yang, Xingxing Huang, 2017).

The representative enterprises of platform-type fresh e-commerce mainly include Alibaba and Jingdong. Miao.tmall.com with 43.8\% market penetration rate fresh e-commerce market dominant, Jingdong fresh with $14.4 \%$ ranked second.

\subsection{Vertical-type fresh e-commerce}

Vertical-type fresh e-commerce mainly refers to the fresh food enterprise or the enterprise that owns the cold chain logistics, these enterprises always operate fresh e-commerce platform to develop their own online business. Vertical-type fresh e-commerce often joins hands with the original places of friut producrs. It can not only ensure the quality of product, but also reduce the loss rate during transportation.

The representative enterprises of vertical-type fresh e-commerce include sfbest.com and benlai.com. Sfbest.com can purchases fresh agricultural products from original places by rely on the logistics network of SF Express. Benlai.com does not have self-built cold chain logistics, but it can find good products from all countries by buyers, and then sell them through the third-party logistics (Shanshan Wang, Xin Yang, Fen Chen, 2016).

\subsection{O2O-type fresh e-commerce}

O2O-type fresh e-commerce adopts the form of order online and experience it offline. Its core idea is that online shops transfer information to customers, such as discounts and promotions information, and then customers can complete an order and pay it online. With the order information, customers can go to the shop to pick up their goods or enjoy the service. It can reduces logistics costs.

As the representative enterprise of O2O-type fresh e-commerce, Yonghui Superstores are widely distributed in most cities of China. It combines online and offline, customers can purchase and pay online, and then pick up their goods at any store. This can greatly reduce the dissatisfaction caused by the inconsistency between online photos and actual objects.

\subsection{New retail-type fresh e-commerce}

O2O-type fresh e-commerce only uses the online platform to attract customers. New retail-type 
fresh e-commerce generally adopt the "online + offli ne + logistics" mode, it always emphasizes the two-way transformation between online and offline.

The representative enterprise of new retail-type fresh e-commerce is Ali's freshhema.com. Since the first store in Shanghai in early 2016, freshhema.com has opened more than 40 stores in Shanghai, Beijing and other places within two years. Most of the stores have achieved profitability. Its business process is shown in the figure1.

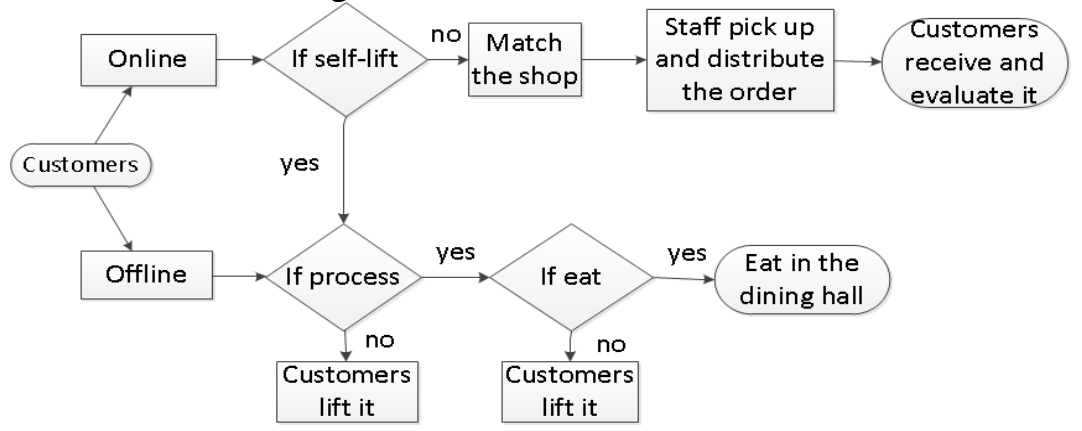

Figure 1 business process of freshhema.com.

\section{Research on the development issues of fresh e-commerce}

The transaction scale of China's fresh e-commerce market has surged from 3.56 billion yuan in 2010 to more than 100 billion yuan in 2017. It has a good development prospect. However, fresh e-commerce has exposed a series of problems in the development process.

\subsection{High cost of cold chain logistics}

Fresh products have a special requirement for storage temperature, and need to use cold chain logistics in transportation. Although the cold chain logistics in China has made relatively great progress after the 12th Five-year Plan, compared with these developed countries, cold chain logistics is lagging behind in China. The living standards of our people are increasing, and the demand for food diversity and safety is also increasing. Whether in terms of quality or quantity, the supply of cold chain logistics in China is far from meeting the needs (Hao Liu, 2016). Due to the lack of cold chain logistics, the cost of it remains high.

\subsection{The coverage of cold chain logistics is unbalanced}

The coverage of cold chain logistics presents a significant regional imbalance, it is not guaranteed in most romote areas (Jingyu Chen, Hui Huang, 2015). China's fresh e-commerce area is mainly distributed in Central South, East China, North China, these areas are relatively developed in agriculture and transport fresh products from the place of production to the place of sale is convenient and fast. The other part is mainly concentrated in Jiangsu, Zhejiang and Shanghai where population consumption is high. However, the coverage of cold chain logistics in western China and other places is obviously unable to meet the needs of consumers, as shown in table 2.

Table 2 The density of cold chain logistics.

\begin{tabular}{cc}
\hline Number & region \\
\hline More than 40 & Beijing, Jiangshu, Zhejiang \\
36 40 & Hubei, Anhui,Fujian, Guangdong \\
31 35 & Neimenggu, Shanxi,Sichuan \\
Less than 30 & Qinghai, Gansu, Yunnan \\
\hline
\end{tabular}




\subsection{The standards are not uniform}

The standards include the quality standards and the industry standards: (1)The quality standards of fresh products are not uniform: different types of fresh products have different characteristics, even the same kinds of fresh products have diffferent taste, weight and size (Chunlin Wu, 2017). Consumers can't touch the products when they buy fresh products online, and they need to compare the sellers in order to pick up high quality friuts. (2)The industry standard of fresh products is not uniform: At present, China does not has a unified industry standard to supervise the field of fresh e-commerce, relevant regulatory systems and laws also need to be improved. Due to the inconsistent standards of each fresh e-commerce platform, the information between online and offline is prone to asymmetry, and resulting in low customer satisfaction.

\subsection{High loss rate during transportationof fresh produce}

Fresh products have regional and timeliness characteristics, it needs cold chain logistics to protect them from deteriorating in the process of transportation. However, due to the lack of advanced technology and hardware facilities, China's cold chain logistics has resulted in higher loss rate during transportation. It is understood that the average loss rate of fresh agricultural products in China is $25 \%-30 \%$, while the average loss rate of developed countries such as Japan is only about $10 \%$. The high loss rate will directly increase the cost of fresh e-commerceand reduce profits. Except that, it will also bring a bad experience to the consumers.

\section{Suggestions for fresh e-commerce development}

(1)Strengthen the construction of cold chain logistics infrastructure and promote the formation of cold chain logistics information integration. Cold chain logistics occupies an important position in the transportation of fresh products, it represents the image of a company and affects the perception of consumers (Yanhong Liu, 2016). So we should vigorously promote the construction of cold chain logistics and the development in a faster and better direction. In addition, information integration also plays an important role in the construction of cold chain logistics (Xiaoya $\mathrm{Ma}, \mathrm{Wu}$ Huang, 2016). China has a large population, and the demand for fresh e-commerce is also very large, and the relevant information data will show explosive growth. Therefore, we need to build a management information system to link information on fresh e-commerce companies, platforms, origins, consumers, etc. It can greatly improve the efficiency of circulation and tracking of agricultural products in logistics, and improve the operational efficiency and level of fresh e-commerce.

(2)Increase policy support and promulgate relevant laws and regulations to promote the unification of fresh industry standards. With the improvement of living standard and consumption level, people's demand for the variety types of fresh products is also increasing. We should invest more manpower, material resources and financial resources to support the development of fresh e-commerce to meet people's needs. In addition, food safety has always been the focus of attention, China's food safety department should pay attention to the quality of fresh products, and promulgate relevant laws and policies to promote the unification of fresh e-commerce industry standards, form a complete food safety guarantee system.

(3)Open up online and offline. Both offline retail and online shopping seem to be competitive. In fact, there is a link between online and offline: Online promotion of offline and offline leads to online, companies can use the advantages of online publicity to divert offline and invite online consumers to the store to experience, or it can promote online shopping when customers shop at a store (Xingtao Kang, 2017). The two complement each other to make the fresh e-commerce reach 
an optimal mode. So it is important to open up barriers between online channels and offline channels. Fresh e-commerce can bring better business results to the company under the general trend of "Internet +" if it really get online and offline.

(4)Target customer groups accurately and adapt to the changes in consumer philosophy. The traditional consumers of fresh retail are mainly housewives for household purchases, while the current fresh e-commerce faces mainly the group of post-80s and post-90s (Bo Ya, 2018). The consumption concept displayed by this group of people is completely different from the elder generation. Most of this group are those who have a good living environment and high quality lifestyle. They care about the quality of fresh products, the diversity of varieties and the convenience of services. Along with the changing trend of the consumer groups, the fresh industry needs to target the customer groups accurately and tailor consumption programs for customers.

\section{Conclusions}

The main point of this paper is as follows: At present, the development of e-commerce in China is quite perfect, but most fresh e-commerce companies are still in a loss and the development of fresh e-commerce needs to be improved. New retail-type fresh e-commerce can combine online sales, offline retail and third-party logistics, it will definitely be the inevitable development trend of fresh e-commerce. Based on this, this paper starts from the current situation of fresh e-commerce development, explores the common problems existing in fresh e-commerce companies, and then puts forward some targeted suggestions.

\section{References}

[1] Jingyu Chen, Hui Huang, 2015. Research on the Status Quo and Development of E-commerce Cold Chain Logistics of Fresh Agricultural Products in China, Science and technology management research. 35(06), pp.179-183.

[2] Linhui Dai, Yuhao Yang, Xingxing Huang, 2017. Research on the Operation Mode of Fresh E-commerce based on O2O platform, China journal of commerce. (09), pp.12-13.

[3] Xingtao Kang, 2017. Research on the Development Trend of Fresh E-commerce in China, Management observer. (20), pp.21-22.

[4] Hao Liu, 2016. Current Status and Development Countermeasures of Cold Chain Logistics of Fresh Agricultural Products, Chinese journal of agricultural resources and regional planning. 37(03), pp.184-186,232.

[5] Yanhong Liu, 2016. Study on the Improvement of Fresh Electricity Suppliers Cold Chain Logistics Service Quality, Journal of Service Science and Management. 09(06).

[6] Xiaoya Ma, Wu Huang, 2016. Research on the Operation Mode of Cold Chain Logistics of Fresh Agricultural Products in Guangxi under the Background of "Internet +", Joyrnal of commercial economics. (04), pp.97-99.

[7] Zhiyong Qin, Jinzhan Feng, 2017. The Impact of "Internet +" on the Operation and Circulation of Fresh E-commerce, Journal Commercial Economics. (19), pp.81-83.

[8] Shanshan Wang, Xin Yang, Fen Chen, 2016. Research on the Operation Mode of Fresh E-commerce in the Age of "Internet +", Chinn Business. (12), pp.25-27.

[9] Chunlin Wu, 2017. Development Status and Breakthrough Path of Fresh E-commerce in China, Logistics \& material handling. 22(S1), pp.56-58.

[10] Bo Xuan, 2018. Case Analysis of Fresh E-commerce Operation Mode, CO-Oerativeconomy \& Science. (03), pp.92-94. 